\title{
Lack of evidence for sufficiently isolated populations of Glossina morsitans submorsitans on the Adamawa Plateau of Cameroon following geometric morphometric analysis
}

\author{
Mbunkah Daniel Achukwi ${ }^{*}$, Jessica Gillingwater ${ }^{2}$, Alexandre Michel Njan Nloga $^{3}$, \\ Gustave Simo ${ }^{4}$ \\ ${ }^{1}$ Institute of Agricultural Research for Development (IRAD), Wakwa Regional Center, Veterinary Research Laboratory, Ngaoundere, \\ Cameroun; *Corresponding Author: achukwi_md@yahoo.co.uk \\ ${ }^{2}$ London School of Hygiene and Tropical Medicine, London, UK \\ ${ }^{3}$ School of Medicine and Veterinary Sciences, University of Ngaoundere, Ngaoundere, Cameroun \\ ${ }^{4}$ Department of Biochemistry, Faculty of Science, University of Dschang, Dschang, Cameroon
}

Received 24 April 2013; revised 21 June 2013; accepted 8 July 2013

Copyright (C) 2013 Mbunkah Daniel Achukwi et al. This is an open access article distributed under the Creative Commons Attribution License, which permits unrestricted use, distribution, and reproduction in any medium, provided the original work is properly cited.

\section{ABSTRACT}

Trypanosomosis remains the number one killer of livestock in spite of efforts made to eradicate tsetse flies in the Adamawa plateau of Cameroon. Acetone-baited Laveissière type biconical traps were pitched at $\mathbf{1 0 0}$ meter intervals in strategic geo-referenced positions in various ecological niches of the landscape for $\mathbf{5}$ consecutive days in selected villages in Mayo Rey, Mbere, Vina and Faro et Deo divisions. All 493 tsetse flies captured in sites other than Mboula were $G$. morsitans submositans. Measurement of different morphometric characters on the wings of each individual fly was undertaken using the Du Jardin package. The data was processed and analysed by "Permutaciones, Analisis Discriminante (PAD)" and "Bootstraps, Analisis en Componentes principales". The three major sampling sites on the plateau yielded similar results as demonstrated by the neighbour joining tree of Mahalanobis distances but tests using PAD showed the differences between group means to be significant $(P<0.05)$ even when the same number of flies was used. Mixing of tsetse populations from the northern lowlands and those on the plateau and Koutine plain could not be ruled out. These preliminary findings suggest that the flies are not from isolated populations and should be considered as populations frequently exchanging migrants. However, molecular genetics techniques are necessary in ad- dition to morphometric analysis to reach more definitive conclusions.

Keywords: Glossina morsitans submositans; Fly Wing; Geometric Morphometry; Adamawa Plateau Cameroon

\section{INTRODUCTION}

Tsetse flies (Diptera: Glossinidae) are vectors of trypanosomes that cause sleeping sickness in humans and nagana in livestock across sub-Saharan Africa. Trypanosomosis has a major negative impact on agriculture, especially on livestock economics, in areas such as the Adamawa Plateau region of Cameroon where livestock breeding is the mainstay of the economy. In the southwest of neighbouring Nigeria sedentary and semi sedentary cattle herds had trypanosomosis prevalence rates of $9.8 \%$ and $42.8 \%$ respectively and more mechanical vectors were caught than Glossina spps: the G. papalis and G. tachinoides caught did not carry any trypanosome infections [1]. In Zambia, $75.1 \%$ of G. m. morsitans blood meals were from cattle, even when other domestic animals (mainly goats, pigs and dogs) were present [2]. Thus tsetse control strategies rely on a detailed understanding of the epidemiology and ecology of tsetse flies and the genetic variation within and among the fly populations.

In sub-Saharan Africa, conventional disease control methods applied have inadequately addressed the problem of trypanosomosis and large scale control operations 
have virtually stopped. Large scale tsetse eradication campaigns instituted earlier in some countries including Cameroon required huge budgetary allocations that most affected countries could not afford on a sustainable basis. Even innovative options like the use of live bait pyrethroid-impregnated cattle against tsetse flies have had problems with efficiency, time input and the high cost of pyrethroid in rural areas. After about thirty years of government efforts to control tsetse on the Cameroon Adamawa Plateau, trypanosomosis still stands out from various surveys [3-5], as the number one killer of cattle. Large scale tsetse clearing activities were stopped in this region in the mid-nineties [6,7]. These tsetse control efforts have had mixed success records; ultimately, they have been unable to prevent re-infestation of tsetse cleared areas [8]. Consequently, there is a need for new sustainable technical approaches that are adapted to existing local farming systems, more efficient and inexpensive.

A pan African approach called "Pan African Tsetse and Trypanosomosis Eradication Campaign" (PATTEC) has been initiated under the support of African heads of states. The objective of this initiative is to eliminate tsetse flies and trypanosomosis in Africa. A critical examination of alternative options to currently employed control strategies which include the use of screens, tsetse traps and area-wide techniques to exterminate pockets of tsetse infestations is urgently needed [9]. The success of these control strategies requires the identification of genetically isolated tsetse populations where elimination can be undertaken. The identification of genetically isolated tsetse populations is the critical point that will direct the choice between elimination and suppression of tsetse flies in a specific area.

Over the past 30 years, several techniques have been used to assess genetic variation of tsetse flies to identify genetically isolated populations. These techniques include allozymes [10-13], microsatellites [14-16], and mitochondrial DNA techniques [12,15,17-19]. These genetic markers have provided useful information on phenotypic and genetic polymorphisms in Glossina species. They have indicated a degree of genetic differentiation between geographically separated tsetse populations. This was surprising given the mobility of the flies combined with expectations derived from population genetics theory [20-22]. The analysis of mitochondrial DNA revealed relatively high levels of haplotype divergence between randomly chosen individuals among four species analysed, including G. morsitans [20]. However, arthropod mitochondrial genomes are small in size (14 25 kilobases) and maternally inherited [23], hence, data interpretation differs from that of variation in nuclear genes.

The number of tsetse loci in the nuclear genome using the techniques sampled for variation to date is relatively limited for microsatellite markers. For example, in Glossina morsitans morsitans a total of 45 allozymes and five microsatellites were analysed by Krafsur [20]. Morphometric analyses have become interesting tools for the study of population genetics $[24,25]$. The first characters to be affected by micro-evolutionary changes are continuous characters. Morphometrics measure these continuous changes and represent a low-cost tool adapted to the study of phenotypic evolution. This tool has shown considerable epidemiological significance for medically important insects such as the vectors of leishmaniasis and Chagas disease in Latin America. Geometric morphometrics allow comparisons of many samples with homologous landmarks, e.g., the vein-patterns on wings. Morphometric analyses are generally simple to perform and easily realizable in most developing countries where trypanosomosis has a major impact on animals and/or humans. This tool can be used to determine how close or distant tsetse fly populations thought to be isolated truly are by normalising other factors such as size and rotation of the wings from the different populations. This technique allows a more sensitive appraisal of the relationship between groups than genetic techniques involving microsatellites [26,27]. Therefore, the technique can be used to reveal the structure of vector populations. If a vector population is found to be sufficiently geographically isolated to prevent casual mixing with other populations, then it may be of interest for future vector control efforts. The present study specifically sought to compare Glossina morsitans submorsitans populations of different sites of the Adamawa region using morphometry of wings.

\section{MATERIALS AND METHODS}

\subsection{Description of the Geographic Location}

The elevations where sampling was undertaken ranged from $487 \mathrm{~m}$ above sea level in the Koutine plain to over $1497 \mathrm{~m}$ on the plateau (Table 1). The Adamawa region has wooded savannah vegetation, a seven months rainy season with moderate temperatures $\left(22^{\circ} \mathrm{C}-28^{\circ} \mathrm{C}\right)$ and the average annual rainfall ranges from $1500 \mathrm{~mm}$ to 1900 $\mathrm{mm}$. More details about these aspects of the study sites have been described [28].

\subsection{Entomological Approach}

This study was conducted in four divisions (Mayo Rey, Mbere, Vina, and Faro et Deo) of the Adamawa Plateau of Cameroon (Figure 1). The sites comprised: one village (Gamba/Benoue National Park) of the Mayo Rey Division, one village (Mboula) of the Mbere Division, two villages (Mangoli, Mbe) of the Vina Division and 
Table 1. Geo-referenced positions of main villages and number of traps pitched in each village.

\begin{tabular}{|c|c|c|c|}
\hline Village & Geo-referenced positions & Height above sea level & Number of traps \\
\hline Mboula & $\begin{array}{l}\text { N06 }^{\circ} \text { 69,366 } \\
\text { E013 }^{\circ} 98,333\end{array}$ & $932 \mathrm{~m}$ & 11 \\
\hline Mangoli & $\begin{array}{c}{\mathrm{N} 07^{\circ}}^{0} 02,841 \\
\mathrm{E}^{\circ} 4^{\circ} 00,819\end{array}$ & $1497 m$ & 25 \\
\hline Guemnfiti & $\begin{array}{l}{\mathrm{N} 07^{\circ}}^{\circ} 67,680 \\
\text { E01 }^{\circ} 18,986\end{array}$ & $511 \mathrm{~m}$ & 21 \\
\hline Kontcha & $\begin{array}{l}\text { N07 }^{\circ} 92,583 \\
\text { E012 }^{\circ} 28,640\end{array}$ & $487 \mathrm{~m}$ & 25 \\
\hline Benoue National Park & $\begin{array}{l}\text { N08 }^{\circ} 12,833 \\
\text { E13 }^{\circ} 39,529\end{array}$ & $538 m$ & 18 \\
\hline
\end{tabular}

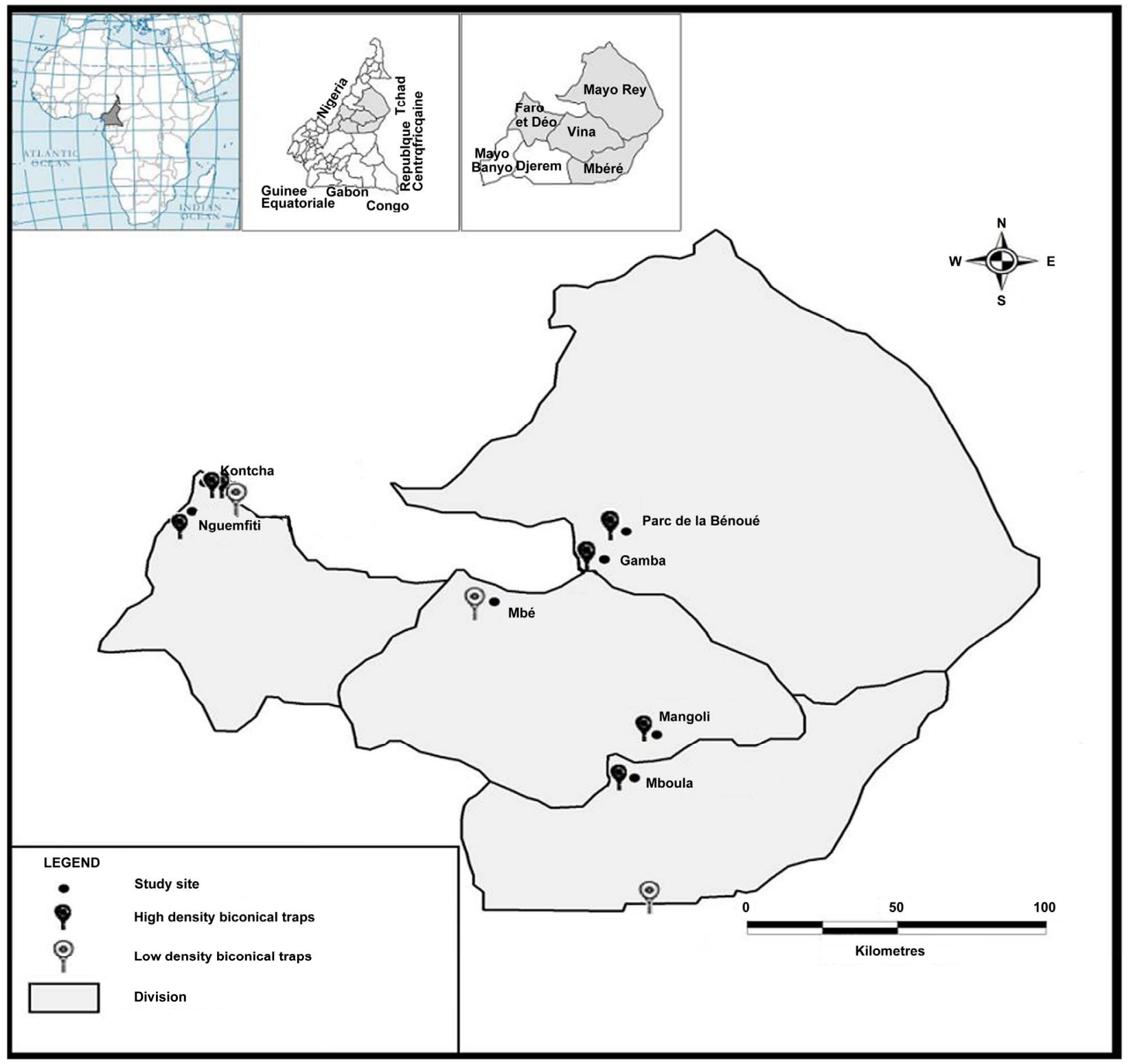

Figure 1. Map of Adamawa region illustrating geo-referenced main positions of bi-conical traps pitched for tsetse fly catching. The intensity of darkness of the trap reflects the abundance (is proportional to the number) of traps placed in the locality. 
two villages (Kontcha, Nguemfiti) of the Faro et Deo Division. Tsetse fly acetone-baited biconical traps [29] were pitched in tsetse fly favourable biotopes in each village. The herdsmen guided the research team in locating tsetse fly biotopes. Geographical coordinates (the main sites in Table 1) for each trap were recorded using a GPS set. Traps were spaced at 100 meter intervals. Tsetse flies were collected twice per day for five consecutive days. The relative G. m. submorsitans population densities (flies/trap/day) for Nguemfiti, Kontcha and Gamba/Benoue National Park trap sites were also determined. Henceforth the site Gamba/Benoue National Park will simply be referred to as the Benoue National Park because they are too close to each other. All flies from each trap were counted, sorted according to sex and species, and were prepared for wing morphometry. With regard to the latter process, the wings were removed, transferred to a glass slide, and covered with a cover slip. The cover slip was sello-tapped onto the glass slide. Slides were labeled with the sex, fly species and trap site co-ordinates. The mounted wing preparations were subsequently scanned into a computer (Figure 2(a)).

\subsection{Morphometrics Analysis}

The size of the wing is known to be proportional to the

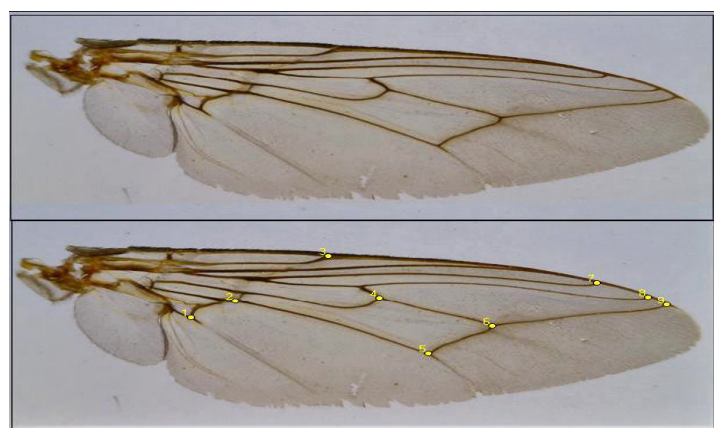

(a)

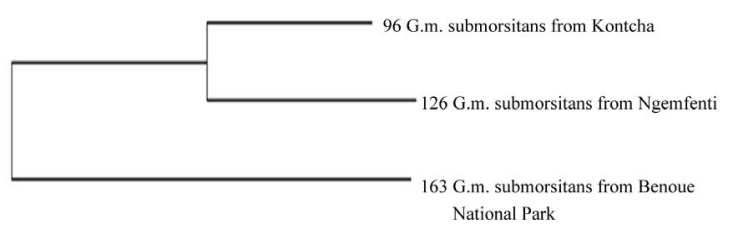

(b)

Figure 2. (a) Above is a scanned image of the dissected wing of a G. morsitans sub morsitans collected from one of the three sampling sites. Below the same image with yellow dots indicating the chosen land-marks for morphometric analysis; (b) Joining tree of Mahalanobis distances. This shows that the fly populations at sites one and two (Kontcha and Nguemfiti) are more closely related to one another than to the population from site 3 (Benoue National Park). size of the individual insect [30]. Here, the features of "COO" (collection of coordinates) software version 37 of Du Jardin package; (http://www.mpl.ird.fr/morphometrics/bac/) were used. This software allows the measurement of different morphometric characters on the wings of each individual. Briefly, digital images of each wing were obtained and the COO software was used to record 9 Cartesian coordinates (homologous points on the wing referred to as landmarks where veins intersect or end (Figure 3(a)) on each wing. The $\mathrm{x}$ and $\mathrm{y}$ coordinates data were then formatted using TET ("Tabla Espacios Tabulaciones") software (version TET 0 45) to allow processing with the MOG ("Morfometria Geometrica") software (version MOG 0 79) which aligns the scanned images and allows comparison of their size and shape producing both partial and relative warps. These were then further examined using PAD ("Permutaciones, Analisis Discriminante") and BAC ("Bootstraps, Analisis en Componentes Principales”) software. Principal components analyses were performed on the covariance matrix (total sample) or the consensus covariance matrix (subdivided sample) of either raw data or size free variables. Statistical significance of the test was estimated according to the angles between first principal components and associated permutation tests. All of the software used for our analyses is contained in Du Jardin package at http://www.mpl.ird.fr/morphometrics/bac/.

\section{RESULTS AND DISCUSSION}

Only the three largest groups of samples were examined since morphometric analysis requires at least twice the number of samples as there are landmarks; thus the smaller collections were ruled out. The biggest differences in wing shape were between the samples collected in the Northern lowlands (Benoue National Park) and those collected from the other two sites. The fly catch in Mbe was very scanty and no flies were caught near Mangoli village. A total of 495 Glossina sps were caught and identified. Of these, 493 were of the G. morsitans sub morsitans group trapped at the three main sites mentioned above. The remaining two flies caught in Mboula were not included in the analysis. The highest catch was in the neighbourhood of Nguemfiti village while the lowest catch was in the jungle neighbourhood of Mboula.

Trapped flies were mainly G. morsitans submorsitans. The relative densities of G. m. submorsitans for the three main trap sites (Nguemfiti, Kontcha and Benoue National Park) were estimated at 9.6, 7.4 and 3.7 flies/ trap/day, respectively. These densities were superior to the index of apparent abundance reported by Mamoudou et al. [31] for other villages in the same region where the present study was undertaken. The differences may simply be due to differences in biotopes as our study sites were more remote and inaccessible than those of Ma- 


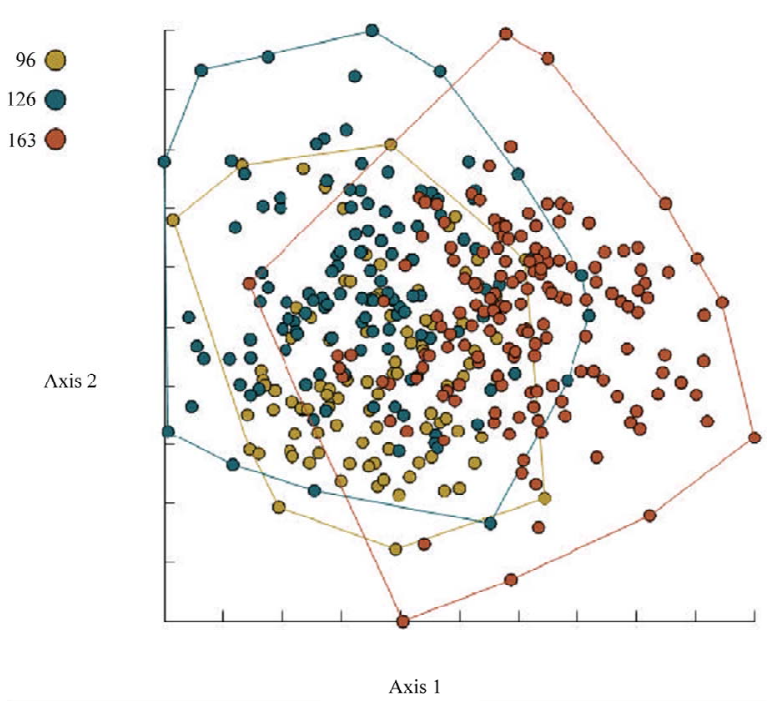

(a)

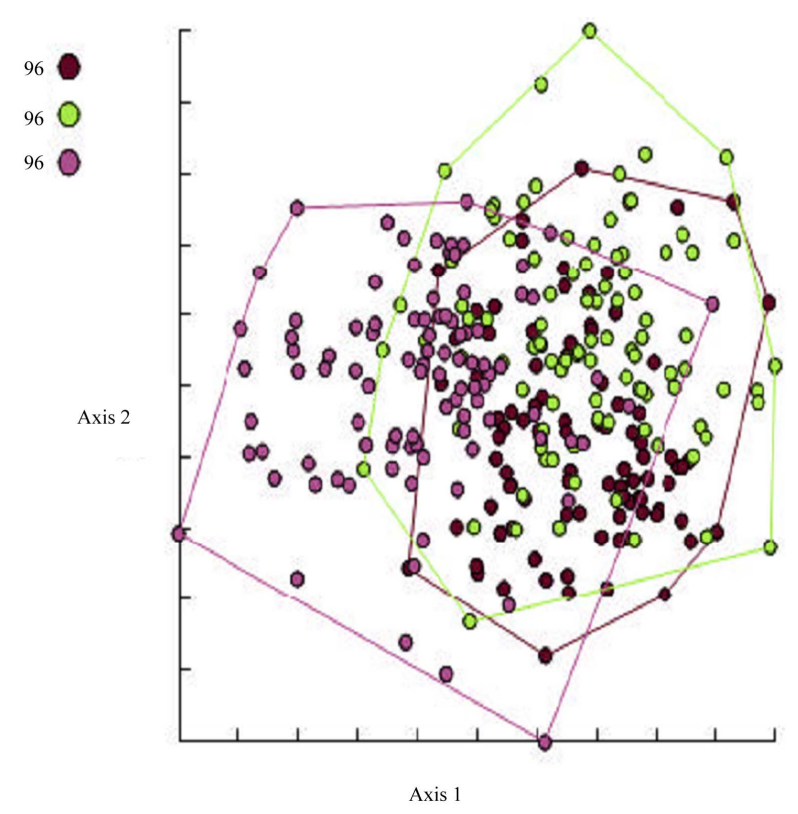

(b)

Figure 3. (a) Results of a principle component analysis run in BAC. The three sampled populations show overlap between the data. The numbers in the key refer to the sample sizes which were 96 for Kontcha (yello), 126 for Nguemfenti (green), and 163 for Gamba (red) at the Benoue National Park. This diagram also clearly shows the more dissimilar northern (Gamba) population overlapping least with the other two; (b) Principle component analysis run in BAC. This time the sample sizes are equal to ensure that it is not the difference in sample size causing the observed differences between the populations. The first 96 samples in each of three groups Kontcha (K), Nguemfeti (N) and Gamba (G) were arbitrarily selected for this analysis.

moudou et al. [31]. During a longitudinal study in the Adamawa region it was found that the incidence of trypanosomosis was high in the valley $(3.7 \%-20 \%)$ and the buffer zone (1.8\% - 13.4\%), and was significantly lower $(0 \%-2.1 \%)$ on the plateau where tsetse clearing had previously been undertaken [31]. They also caught mainly Glossina morsitans submorsitans and a few G. tachinoides in the valley and the buffer zone, but none on the plateau and concluded that the distribution of tsetse, in a large part of the valley, undergoes substantial seasonal changes depending on either the presence or absence of cattle. Other studies undertaken to the north of Kontcha (also one of the sites in the present study) in villages around Poli near the Faro National Park [3] showed a parasite detectable trypanosomosis prevalence rate of $14.3 \%$ in cattle. A consequence of the negative impact of the trypanosomosis in the Adamawa and northern regions of Cameroon is that huge quantities of trypanocides are sold to farmers by vet pharmacies in these regions [32].

Results of the joining tree of Mahalanobis distances (Figure 2(b)) suggest a subdivision of G. m. submorsistans on the Adamawa Plateau according to the sampling sites. Looking at the permutation analysis, it appears that the two major sampling sites on the plateau yielded much more similar results as demonstrated by the neighbour joining tree of Mahalanobis distances (Figure 2(b)). These results were confirmed by a permutation test using PAD. The PAD showed significant $(\mathrm{P}<0.05)$ differences (Figure 3(a)) between tsetse populations from different capture sites. To ensure that the observed differences between the tsetse populations were not due to differences in sample sizes alone, the same analysis was performed using equal sample sizes for all three groups (Figure 3(b)); the same result was obtained. Consequently, morphometric analysis can be used to differenttiate Glossina m. submorsistans from the Adamawa Plateau of Cameroon and this technique can reveal differences between vectors of medical and veterinary importance. The geometric morphometrics technique allows a more sensitive appraisal of the relationships between groups than genetic techniques involving microsatellites $[26,33]$. Geometric morphometrics techniques are useful in evaluating the micro-evolutionary changes occurring during phenotypic evolution in tsetse flies, especially in developing countries where laboratories to perform genetic analyses are lacking. These techniques are valuable to the Pan African Tsetse and Trypanosomiasis Eradication Campaign which envisages eradication of tsetse flies from the African continent. Most countries infested by tsetse flies are poor and have few laboratories capable of genetic analyses. Several tsetse fly species are found in some tsetse infested areas. In such areas, the geometric morphometrics technique will be of great value because differences between tsetse species can be easily evaluated. In environments with different tsetse species, specific markers for each species must be developed if ge- 
netic analysis techniques are required. The use of genetic techniques can be time consuming and expensive.

Despite the morphometric differences observed between tsetse populations from different sites, the permutation analysis test showed some identical phonetic characters for some flies sampled at different capture sites (Figures 3(a) and (b)). These results indicate that mixtures of tsetse fly populations may exist, the sampling site notwithstanding. The presence of mixed tsetse fly populations at each capture site can be explained by the exchange of tsetse flies between different sampling sites. The probability of a tsetse fly to fly from one sample site to another is low because of the distance between sites. However, during transhumance, it is likely that livestock transport a few tsetse flies between sites.

The flies in the sampled areas on the Cameroon Adamawa Plateau, although different, are not from sufficiently isolated populations to allow treatment for the purposes of elimination. These flies should be considered as populations which are able to exchange migrants, especially through the movement of livestock. The necessity for geographic isolation for eradication makes islands ideal targets for such strategies. This was demonstrated in 1979 using SIT with G. austeni from Unguja Island of Zanzibar [34]. Mainland vector populations are considerably harder to define and delineate, especially where several species are present as in the Southern part of the Adamawa Plateau where both G. morsitans submositans and G. tachinoides are found. However, artificial barriers such as screens and traps impregnated with insecticides may be useful during initial control interventions in mainland vector populations.

The present study shows that the natural reserve parks are a safe haven for tsetse flies and are major sources for acquisition of trypanosomosis by domesticated livestock. The predominant livestock is cattle in the Adamawa Plateau, which move in and out of these reserves in search of fodder. Villages like Nguemfiti, Kontcha and Gamba (Benoue National Park) which are near national parks in this region have very high tsetse fly densities. Future studies could be directed towards DNA sequence analyses of tsetse flies, estimating the vectorial capacity of the flies and relating this index to trypanosome infection rates of inhabitants, both humans and animals. The present findings may be valuable in establishing practical guidelines for tsetse fly control strategies in the region in partnership with neighbouring countries.

\section{ACKNOWLEDGEMENTS}

This work received financial support from Leverhulme Trust and material assistance from Vestergaard and the Institute of Agricultural research for development (IRAD) Cameroon. The field work received technical assistance from Dr. Bouyer Jeremy (CIRAD-CIRDES Burkina Faso), the rural field staff of MINEPIA Cameroon headed by $\mathrm{Mr}$.
Samuel Abba and Ministry of health for which we are grateful. We are also grateful to Dr. Manchang TK, Mr. Mforpit Y. Mrs. Wachong-Kum HNF and Faustin Samba, all of IRAD Wakwa, who provided valuable logistical assistance during some of the field trips.

\section{REFERENCES}

[1] Ogunsanmi, A.O., Ikede, B.O. and Akpavie, S.O. (2000) Effects of management, season, vegetation zone and breed on the prevalence of bovine trypanosomiasis in south western Nigeria. Israel Journal of Veterinary Medicine, 55, 69-73.

[2] Bossche, P.V.D. and Staak, C. (1997) The importance of cattle as a food source for Glossina morsitans morsitans in Katete District, Eastern Province, Zambia. Acta Tropica, 65, 105-109. doi:10.1016/S0001-706X(97)00658-X

[3] Achukwi, M.D. and Musongong, G.A. (2009) Trypanosomosis in the Dayo/Namchi (Bos taurus) and zebu White Fulani (Bos indicus) cattle in Faro Division, North Cameroon. Journal of Applied Biosciences, 15, 807-814.

[4] Mamoudou, A., Zoli, A. and Tchoua, P. (2009) Parasitological prevalence of bovine trypanosomosis in the Faro and Deo division of the Adamawa plateau, Cameroon. International Journal of Biological and Chemical Sciences, 3, 1192-1197.

[5] Tanenbe, C., Gambo, H., Musongong, A.G., Boris, O. and Achukwi, M.D. (2010) Prévalence de la trypanosomose bovine dans les départements du Faro et Déo, et de la Vina au Cameroun: Bilan de vingt années de lutte contre les glossines. Revue d'élevage et de médecine Vétérinaire des Pays Tropicaux, 63, 53-55.

[6] Cuisance, D. (1991) Lutte contre les Glossines dans l 'Adamaoua (Cameroun) Bilan de Situation et Recommendations. Institut d'Elevage et de Médecine Vétérinaire des Pays Tropicaux, Département du CIRAD, Maison Alfort, 1-53.

[7] Cuisance, D. and Boutrais, J. (1995) Evaluation de la Situation et de la Stratégie de Lutte contre les Glossines et les Trypanosomoses dans l 'Adamaoua (Cameroun). Rapport de Mission CIRADEMVT, Maison Alfort, 1-63.

[8] Awa, D. and Achukwi, M.D. (2010) Livestock pathology in the Central African region: Some epidemiological considerations and control strategies. Animal Health Research Review, 15, 1-10.

[9] Kabayo, J.P. (2002) Aiming to eliminate tsetse from Africa. Trends Parasitology, 18, 473-475. doi:10.1016/S1471-4922(02)02371-1

[10] Gooding, R.H. (1981) Genetic polymorphism in three species of tsetse flies (Diptera: Glossinidae) in Upper Volta. Acta Tropica, 38, 149-161

[11] Gooding, R.H. (1989) Genetics of two populations of Glossina morsitans centralis (Diptera: Glossinidae) from Zambia. Acta Tropica, 46, 17-22. doi:10.1016/0001-706X(89)90012-0

[12] Gooding, R.H., Mbise, S., Macha, P. and Rolseth, B.M. (1993) Genetic variation in a Tanzanian population of Glossina swynnertoni (Diptera: Glossinidae). Journal of Medical Entomology, 30, 489-492. 
[13] Krafsur, E.S. (2002) Population structure of the tsetse fly Glossina pallidipes estimated by allozyme, microsatellite and mitochondrial gene diversities. Insect Molecular Biology, 11, 37-45. doi:10.1046/j.0962-1075.2001.00307.X

[14] Solano, P., Duvallet, G., Dumas, V., Cuisance, D. and Cuny, G. (1997) Microsatellite markers for genetic population studies in Glossina palpalis (Diptera: Glossinidae). Acta Tropica, 65, 175-180. doi:10.1016/S0001-706X(97)00663-3

[15] Ouma, J.O., Cummings, M.A., Jones, K.C. and Krafsur, E.S. (2003) Characterization of microsatellite markers in the tsetse fly, Glossina pallidipes (Diptera: Glossinidae). Molecular Ecology Notes, 3, 450-453. doi:10.1046/j.1471-8286.2003.00480.x

[16] Krafsur, E.S. and Endsley, M.A. (2006) Shared microsatellite loci in Glossina morsitans sensulato (Diptera: Glossinidae). Journal of Medical Entomology, 43, 640-642. doi:10.1603/0022-2585(2006)43[640:SMLIGM]2.0.CO;2

[17] Krafsur, E.S. and Griffiths, N. (1997) Genetic variation at structural loci in the Glossina morsitans species group. Biochemical Genetic, 35, 1-11. doi:10.1023/A:1022252311715

[18] Krafsur, E.S. and Wohlford, D.L. (1999) Breeding structure of Glossina pallidipes populations evaluated by mitochondrial variation. Journal of Heredity, 90, 635-642. doi:10.1093/jhered/90.6.635

[19] Marquez, J.G., Vreysen, M.J., Robinson, A.S., Bado, S., and Krafsur, E.S. (2004) Mitochondrial diversity analysis of Glossina palpalis gambiensis from Mali and Senegal. Medical and Veterinary Entomology, 18, 288-295. doi:10.1111/j.0269-283X.2004.00508.X

[20] Krafsur, E.S. (2003) Tsetse fly population genetics: An indirect approach to dispersal. Trendsin Parasitology, 19, 162-166. doi:10.1016/S1471-4922(03)00034-5

[21] Krafsur, E.S. (2009) Tsetse flies: Genetics, evolution, and role as vectors. Infections, Genetic and Evolution, 9, 124141. doi:10.1016/i.meegid.2008.09.010

[22] Gooding, R.H. and Krafsur, E.S. (2005) Tsetse genetics: Contributions to biology, systematics, and control of tsetse flies. Annual Review of Entomology, 50, 101-123. doi:10.1146/annurev.ento.50.071803.130443

[23] Jeyaprakash, A. and Hoy, M.A. (2009) First divergence time of spiders, scorpions, mites and ticks (sub-phylum Chelicerata) inferred from mitochondrial phylogeny. $E x-$ primental Applied Acarology. 47, 1-18. doi:10.1007/s10493-008-9203-5

[24] Solano, P., De La Rocque, S., Cuisance, D., Geoffroy, B., De Meeus, T., Cuny, G. and Duvallet, G. (1999) Intraspecific variability in natural populations of Glossina palpalis gambiensis from West Africa, revealed by genetic and morphometric analyses. Medical and Veterinary Entomology, 13, 401-407. doi:10.1046/j.1365-2915.1999.00189.x

[25] Vignon, M. and Sasal, P. (2010) The use of geometric morphometrics in understanding shape variability of scle- rotized haptoral structures of monogeneans (Platyhelminthes) with insights into biogeographic variability. $\mathrm{Pa}$ rasitology International, 59, 183-191. doi:10.1016/j.parint.2010.01.006

[26] Bouyer, J., Ravel, S., Dujardin, J.P., De Meeüs, T., Vial, L., Thévenon, S., Guerrini, L., Sidibé, I. and Solano, P. (2007) Population structuring of Glossina palpalis gambiensis (Diptera: Glossinidae) according to landscape fragmentation in the Mouhoun river, Burkina Faso. Journal of Medical Entomology, 44, 788-795. doi:10.1603/0022-2585(2007)44[788:PSOGPG]2.0.CO;2

[27] Camara, M., Carorian, H.O, Ravel, S, Dujardin, J.P., Hervouet, J.P., De Meeus, T., Kagbadouno, M.S., Bouyer, J. and Solano, P. (2006) Genetic and morphometric evidence for population isolation of Glossina palpalis gambiensis (Diptera: Glossinidae) on the Loos Islands, Guinea. Journal of MedicalEntomology, 43, 853-860. doi:10.1603/0022-2585(2006)43[853:GAMEFP]2.0.CO;2

[28] Letouzey, R. (1969) Etude phytogéographique du cameroun. Le Chevalier, Paris, 1-513.

[29] Gouteux, J.P. and Lancien, J. (1986) The pyramidal trap for collecting and controlling tsetse flies (Diptera: Glossinidae). Comparative trials and description of new collecting technics. Tropical Medicine and Parasitology, 37, 61-66.

[30] Patterson, J.S. and Schofield, C.J. (2005) Preliminary study of wing morphometry in relation to tsetse population genetics. South African Journal of Science, 101, 132134.

[31] Mamoudou, A., Zoli, A., Hamadama, H., Bourdanne, Abah, S., Geerts, S., Clausen, P.H., Zessin, K.H., Kyule, M. and Van Den Bossche, P. (2008) Seasonal distribution and abundance of tsetse flies (Glossina spp) in the Faro and Deo Division of the Adamaoua Plateau in Cameroon. Medical and Veterinary Entomology, 22, 32-36. doi:10.1111/j.1365-2915.2008.00711.x

[32] Awa, D.N., Achukwi, M.D., Manchang, T.K., Enam, J., Tenghe, A.M.M., Niba, E., Mfopit, M.Y. and Nain, C.W. (2009) The veterinary input sector and animal health management in traditional livestock systems of north Cameroon. 3èmes Journées de Recherches en Sciences sociales. INRA, SFER, CIRAD, Montpellier.

[33] Mamoudou, A., Zoli, A., Mbahin, N., Tanenbe, C., Bourdanne, Clausen, P.H., Marcotty, T., Van den Bossche P. and Geerts, S. (2006) Prevalence and incidence of bovine trypanosomosis on the Adamaoua plateau in Cameroon 10 years after the tsetse eradication campaign. Veterinary Parasitology, 142, 16-22. doi:10.1016/j.vetpar.2006.06.033

[34] Vreysen, M.J.B., Saleh, K.M., Ali, M.Y., Abdullah, M.A., Zhu, Z.R., Juma, K.G., Dyck, V.A., Masangi, A.R., Mkonyi, P.M. and Feldmann, H.U. (2000) Glossina austeni (Diptera: Glossinidae) eradicated on the Island of Unguja, Zanzibar, using the sterile insect technique. Journal of Economic Entomology, 93, 123-135. doi:10.1603/0022-0493-93.1.123 